\title{
Regulations of granule-bound starch synthase I gene expression in rice leaves by temperature and drought stress
}

\author{
S.J. WANG*, L.F. LIU, C.K. CHEN and L.W. CHEN \\ Department of Agronomy, National Taiwan University, 1, Section 4, Roosevelt Rd., Taipei 106, Taiwan
}

\begin{abstract}
Effects of temperature $\left(15 / 10,25 / 20,30 / 25\right.$, and $\left.35 / 30{ }^{\circ} \mathrm{C}\right)$ and drought stresses on the expression of granule-bound starch synthase I (GBSSI) gene were examined in rice (Oryza sativa L.) seedlings. The GBSSI expression was higher at the low temperature $\left(15 / 10{ }^{\circ} \mathrm{C}\right)$, and the transcript level decreased at temperatures higher than $30{ }^{\circ} \mathrm{C}$. Protein phosphorylation was involved in the low temperature-stimulated signal transduction of GBSSI regulation. The expression of GBSSI in rice seedling was reduced under a drought stress. Even though exogenous ABA played a role to reduce the GBSSI transcript accumulation under non-stress condition, the reducing of GBSSI expression by drought stress appeared to be mediated by an ABA-independent pathway.
\end{abstract}

Additional key words: abscisic acid, Oryza sativa.

\section{Introduction}

Accumulation of starch has been recognized as a major factor for determining the yield of agronomic crops. Starch is a polymer complex consisting of amylose and amylopectin. In general, the ratio of amylose to amylopectin is about $1: 3$, but the ratio vary in different plant species (Manners 1985). Starch synthase is a group of important enzymes involved in the synthesis of amylose and amylopectin, and it may be further classified into two major types according to their distributions in the amyloplast, namely granule-bound starch synthase (GBSS) and soluble starch synthase (SSS). For GBSS, there are two isoforms, GBSSI and GBSSII. GBSSI, also known as the WAXY protein, is tightly bound to starch granules and has a molecular mass of 58 - $60 \mathrm{kDa}$. This enzyme provides the largest proportion of total GBSS activity (Dry et al. 1992), and is the major enzyme responsible for amylose synthesis (Tsai 1974). The role of SSS is not clear; however, this enzyme also contains several isoforms, SSI, SSII, SSIII and SSIV (Marshall et al. 1996, Dian et al. 2005).

Environmental factors are also important in affecting starch quality and quantity. Water deficits up to -0.72 MPa stimulated sucrose synthesis and decreased starch synthesis in potato tubers (Geigenberger et al. 1999a,b). Temperature stress also reduced starch content in wheat grains (Chinnusamy and Khanna-Chopra 2003). A decrease in the activity of SSS under high temperatures was observed in wheat (Keeling et al. 1993), but not in maize and rice (Cao et al. 2000, Jiang et al. 2003). However, decreases in activities of ADP-glucose pyrophosphorylase has been observed both in maize kernels and wheat endosperms under heat stresses, thus resulting in a reduction of starch synthesis (Keeling et al. 1993, Wilhelm et al. 1999). It has been shown that the amylose content in rice grains was reduced under a heat stress, but increased at cool conditions (Asaoka et al. 1985, Hirano and Sano 1998). Besides, the branch chain pattern of amylopectin could also be changed by temperatures, and it was suggested that a reduced activity of branching enzyme at high temperatures is a significant factor limiting the branching frequency (Jiang et al. 2003). Although environmental factors have significant effects on starch synthesis, their regulatory mechanisms remain unclear.

In order to better understand the effect of abiotic stresses on starch synthesis, GBSSI was used as a marker gene to study its expression and regulation in rice seedlings under temperature and drought stresses.

Received 11 February 2005, accepted 9 August 2005.

Abbreviations: ABA - abscisic acid; CHX - cycloheximide; GBSSI - granule-bound starch synthase I; SSS - soluble starch synthase. Acknowledgements: We are grateful to Dr. Chia-Yin Tsai for reading the manuscript. This research was supported by a grant from the National Science Council of the Republic of China and Council of Agriculture Executive Yuan in Taiwan.

* Corresponding author; fax: (+886) 233664787 ext. 102, e-mail: shujen@ntu.edu.tw 


\section{Materials and methods}

Plants and stress treatments: Rice (Oryza sativa L. cv. Tainung 67) seeds were sterilized in $2.65 \%$ sodium hypochlorite with Tween 20 for 15 min and subsequently washed with distilled $\mathrm{H}_{2} \mathrm{O}$ for three times. Seeds were then germinated at $28{ }^{\circ} \mathrm{C}$ in dark for $2 \mathrm{~d}$, and then they were moved to the phytotron (Agricultural Experimental Station, National Taiwan University, Taipei, Taiwan) for growing in half-strength Kimura $\mathrm{B}$ nutrition solution (Chu and Lee 1989) at $30 / 25{ }^{\circ} \mathrm{C}$ under the natural light and $90 \%$ of relative humidity. The seedlings with 3 leaves were moved to other phytotrons with various temperatures, i.e., $15 / 10,25 / 20$ or $35 / 30{ }^{\circ} \mathrm{C}$ for 24 , 48 and $72 \mathrm{~h}$, respectively. Seedlings left at $30 / 25^{\circ} \mathrm{C}$ were used as the control. For drought stress treatments, rice seedlings were removed from medium and desiccated in Petri dishes with filter paper for various periods at $30 / 25{ }^{\circ} \mathrm{C}$ (Seki et al. 2002). For detection the effect of abscisic acid (ABA) on GBSSI expression, rice seedlings were cultured on 50, 100 and $200 \mu \mathrm{M}$ ABA - contained Kimura B solution for $24 \mathrm{~h}$ before the leaf samples were collected for GBSSI expression analysis. To analyze the role of ABA on GBSSI expression under a drought stress condition, rice seedlings were pre-cultured with $200 \mu \mathrm{M}$ ABA or $200 \mu \mathrm{M}$ fluridone (an ABA-synthesis inhibitor) contained nutrition solutions for $24 \mathrm{~h}$ before the airdrying treatment for $12 \mathrm{~h}$. To evaluate effects of various inhibitors on protein synthesis, protein kinases and phosphatases on the low temperature-stimulated GBSSI expression, rice seedlings were pretreated with various inhibitors contained nutrition solutions for $1 \mathrm{~h}$ before the low temperature treatment. The final concentrations of

\section{Results and discussion}

Effects of temperature on the GBSSI expression: Temperature is an important factor to determine crop growth and development. For example, high temperature reduced the seed germination percentage and rate in pearl millet and maize; moreover, heat stress also significantly affected the vegetative growth of maize (Ashraf and Hafeez 2004). Temperature stress affected gene expressions were also observed in several species (Sun et al. 2002, Shinozaki et al. 2003). In this study report, Northern blot hybridization showed that the expression of GBSSI gene was higher at the low temperature $\left(15 / 10^{\circ} \mathrm{C}\right)$ than at the control $\left(30 / 25{ }^{\circ} \mathrm{C}\right)$ or high temperature $\left(35 / 30{ }^{\circ} \mathrm{C}\right)$ treatment for $24 \mathrm{~h}$ (Fig. 1). The differences became more significant as the treatment was extended to 72 h (Fig. 1). Basically, this result was consistent with the observation where amylose content in rice endosperm was found to increase at cool conditions (Asaoka et al. 1985). Increase in the GBSSI activity at low-temperature presumably would cause the accumulation of more amylose during grain development, thus reducing the grain quality (Suzuki et al. 2002). Although a rice mutant inhibitors of protein synthesis, kinase and phosphatase were $100 \mu \mathrm{M}, 1 \mu \mathrm{M}$ and $0.5 \mu \mathrm{M}$, respectively.

RNA extraction from rice leaves: RNA was isolated from rice leaves using Trizol reagent (Invitrogen, CA, USA). The second and third leaves (counting leaves were began from the leaf next to coleoptile as the first leaf) were harvested, and $100 \mathrm{mg}$ of leaves was homogenized in $1 \mathrm{~cm}^{3}$ Trizol reagent before centrifuging at $10000 \mathrm{~g}$. The supernatant was treated with $0.2 \mathrm{~cm}^{3}$ chloroform, and shake for $15 \mathrm{~s}$ before incubating at room temperature for $3 \mathrm{~min}$. The upper layer solution was transferred to a new tube after centrifugation at $12000 \mathrm{~g}$ for $15 \mathrm{~min}$ at $4{ }^{\circ} \mathrm{C}$. RNA was precipitated with $0.5 \mathrm{~cm}^{3}$ isopropanol and incubated for $10 \mathrm{~min}$ at room temperature. After centrifugation, the pellet was dissolved in $\mathrm{H}_{2} \mathrm{O}$ completely.

Northern blot analysis: Total RNAs (10 $\mu \mathrm{g})$ were separated on $1 \%$ formaldehyde-agarose gels and transferred to the nylon membrane. The partial GBSSI cDNA probe was radioactively labeled with $\alpha-{ }^{32} \mathrm{P}-\mathrm{dCTP}$ using a random primer labeling kit (Amersham Biosciences, Buckinghamshire, UK). After hybridization, the membrane was washed twice with $2 \times$ SSC $\left(1 \mathrm{dm}^{3}\right.$ of $20 \times$ SSC stock solution contained $175.3 \mathrm{~g}$ of $\mathrm{NaCl}$ and $88.2 \mathrm{~g}$ of sodium citrate, $\mathrm{pH} 7.0)$ containing $0.1 \%(\mathrm{~m} / \mathrm{v})$ SDS at room temperature for $30 \mathrm{~min}$ and twice with $0.1 \times$ SSC containing $0.1 \%(\mathrm{~m} / \mathrm{v})$ SDS at $55{ }^{\circ} \mathrm{C}$ for $30 \mathrm{~min}$. EtBr-stained rRNA patterns were used as internal standards in all Northern blot analysis data. Accumulation of GBSSI mRNA was quantified from the Northern blot using image analysis system (Wang et al. 2001).

insensitive to cool temperatures on amylose synthesis has been isolated (Suzuki et al. 2002), which could facilitate the study of temperature effect, the molecular mechanism of low-temperature regulating GBSSI expression is still unclear. In order to study the regulatory mechanism of low-temperature effect on GBSSI gene expression,

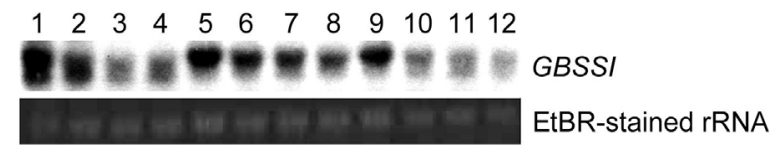

Fig. 1. Effects of temperature on the GBSSI expression in rice leaves. Rice seedlings with three leaves were moved from $30 / 25{ }^{\circ} \mathrm{C}$ to $15 / 10,25 / 20$, and $35 / 30{ }^{\circ} \mathrm{C}$, respectively. After different temperature-treatment for 24 (lane 1 - 4), 48 (lane $5-8$ ) and 72 h (lane 9 - 12), the RNAs were extracted from leaves. GBSSI expressions were determined by Northern blot hybridization with $\alpha-{ }^{32} \mathrm{P}$-dCTP-labeled partial GBSSI cDNA as a probe. Seedlings were exposed at $15 / 10{ }^{\circ} \mathrm{C}$ (lane $1,5,9$ ), at $25 / 20^{\circ} \mathrm{C}$ (lane 2, 6, and 10), at $30 / 25^{\circ} \mathrm{C}$ (lane 3, 7 and 11), and at $35 / 30{ }^{\circ} \mathrm{C}$ (lane 4,8 and 12 ) before samples were collected. 
several protein-synthesis and protein-modification inhibitors were applied to culture media. A pretreatment with $100 \mu \mathrm{M}$ cycloheximide (CHX) for $1 \mathrm{~h}$ had no significant effect on the expression of GBSSI gene stimulated by the low temperature (Fig. 2A). This result

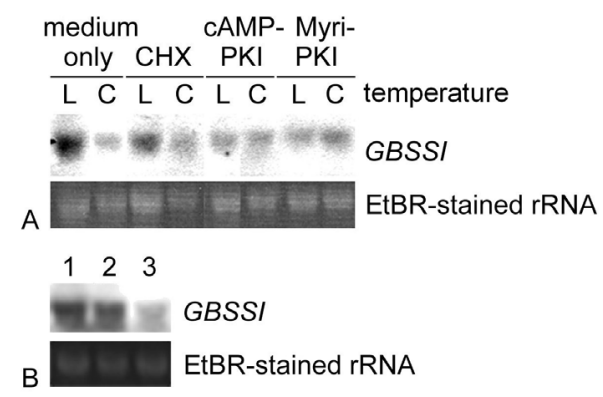

Fig. 2. Northern blot analysis of the low temperature-stimulated GBSSI expressions following treatments with cycloheximide (CHX), protein kinase or phosphatase inhibitors. A - Effects of CHX and protein kinase inhibitors on the low temperaturestimulated GBSSI gene expressions. Rice seedlings were pretreated for $1 \mathrm{~h}$ with $100 \mu \mathrm{M}$ of $\mathrm{CHX}, 1 \mu \mathrm{M}$ cAMPdependent protein kinase inhibitor (cAMP-PKI) or $1 \mu \mathrm{M}$ myristoylated protein kinase $\mathrm{C}$ inhibitor (Myri-PKI), before transferring to the $15 / 10{ }^{\circ} \mathrm{C}$. After the low temperature treatment for $24 \mathrm{~h}$, the RNA was extracted from leaves. $\mathrm{L}$ - indicated low temperature $\left(15 / 10{ }^{\circ} \mathrm{C}\right)$ treatment. C - indicated control temperature $\left(30 / 25{ }^{\circ} \mathrm{C}\right)$ treatment. $B$ - Effect of phosphatase inhibitors on the low temperaturestimulated GBSSI gene expressions. Rice seedlings were pretreated with $0.5 \mu \mathrm{M}$ okadaic acid for $1 \mathrm{~h}$ before they were moved to the $15 / 10{ }^{\circ} \mathrm{C}$ (lane 1) and $25 / 20{ }^{\circ} \mathrm{C}$ (lane 2), respectively. Rice seedlings were maintained in normal medium at $30 / 25{ }^{\circ} \mathrm{C}$ (lane 3) as the control. GBSSI mRNA was determined by the Northern blot hybridization.

suggested that synthesis of de novo protein was not necessary for regulating the transcription of GBSSI gene at low-temperature environments. Therefore, modifications of pre-existed proteins might be involved in the signal transduction of temperature-regulated GBSSI transcription. For analyzing whether protein phosphorylation was involved in the low temperature-related signal transduction for GBSSI gene expressions, effects of cAMP-dependent protein kinase inhibitor and myristoylated protein kinase $\mathrm{C}$ inhibitor were examined. The results showed that the low temperature effect on GBSSI gene expression was repressed by these two kinds of protein kinase inhibitors (Fig. 2A). On the other hand, okadaic acid, a selective inhibitor of protein phosphatase types 1 and 2A (Cohen 1989), did not affect the GBSSI expression response to low temperature (Fig. 2B). These results suggested an involvement of protein phosphorylation in the transduction pathway. However, we could not rule out the possibility that changes in GBSSI expression due to inhibitor treatments might be the result of an indirect effect, especially since GBSSI is the final enzyme in the biosynthetic pathway of starch.
Effects of drought stress on the GBSSI expression in rice leaves: While low temperatures appeared to stimulate GBSSI expressions, GBSSI transcript accumulation was found to be reduced under a drought stress (Fig. 3). The GBSSI expression in the control condition showed a fluctuation pattern during a diurnal cycle. The peak of GBSSI accumulation was observed in the morning (08:00), and then the expression of GBSSI decreased gradually (Fig. 3). This pattern was similar

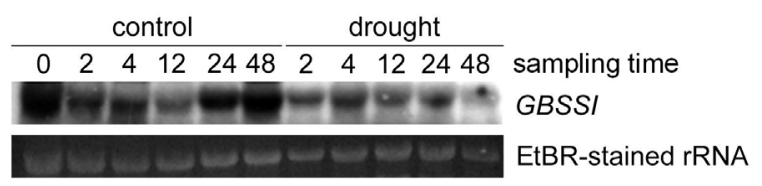

Fig. 3. Effects of drought stress on the GBSSI expression in rice leaves. Rice seedlings were treated with drought stress by airdrying for 2, 4, 12, 24 and $48 \mathrm{~h}$, respectively. The control samples were cultured in the culture medium, and the leaf samples were harvested from 08:00 (sampling time was indicated as 0). Expressions of GBSSI gene were determined by Northern blot hybridization.

to the circadian expression of GBSSI gene found in sweet potato leaves (Wang et al. 1999, 2001, 2004) and snapdragon (Mérida et al. 1999). In addition to GBSSI gene, the circadian expression of GBSSII was also been demonstrated in rice (Dian et al. 2003). Besides, the diurnal activity changes of sucrose-phosphate synthase, a key enzyme for sucrose and starch metabolism, have been observed in Prosopis juliflora leaves (Pathre et al. 2004). But the fluctuation of sucrose-phosphate synthase activity was controlled by environmental factors, was not regulated by circadian clock. Under the drought stress, the expression of GBSSI gene could still be detected until air-drying for $48 \mathrm{~h}$; however, the expression levels under drought were lower than that of the control, and also appeared to abolish the circadian expression of GBSSI (Fig. 3). Since ADP-glucose pyrophosphorylase was also decreased under water stress in potato (Geigenberger et al. 1999a), it was suggested that starch synthesis could be affected by drought stress.

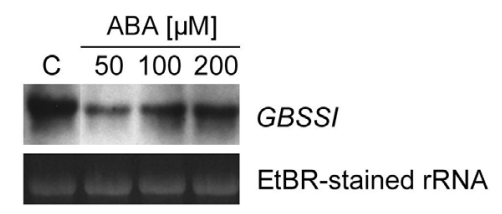

Fig. 4. Effects of ABA on the GBSSI expression in rice leaves. Rice seedlings were cultured in 50, 100, and $200 \mu \mathrm{M} \mathrm{ABA-}$ contained medium for $24 \mathrm{~h}$ before the leaf samples were collected. GBSSI mRNA was determined by Northern blot hybridization. C - indicated the control rice seedlings cultured in normal condition.

Many genes responded to drought stress have been observed, and both ABA-dependent and ABAindependent regulatory pathway were involved in 
controlling the expression of drought stress-responsive genes (Shinozaki and Yamaguchi-Shinozaki 2000, Xiong et al. 2002). Two major cis-acting elements, ABAresponsive element (ABRE) and dehydration-responsive element (DRE)/C-repeat (CRT), have been identified in the promoter of drought-responsive genes with the ABRE element functioning in the ABA-dependent and DRE/CRT in the ABA-independent pathway (Shinozaki et al. 2003). In this study, rice seedlings were treated with different concentration of ABA for $24 \mathrm{~h}$, and following the GBSSI expression was determined. The result

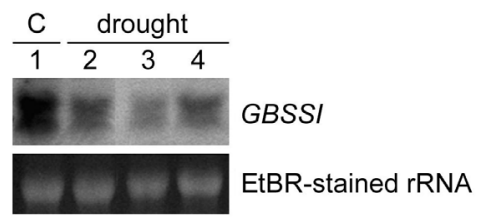

Fig. 5. ABA effects on the drought-regulated GBSSI expression in rice seedling. Lane 1 - rice seedlings were cultured in the normal medium as controls. Lanes 2, 3 and 4 - rice seedlings were treated with drought stress. Lanes 3 and 4 - seedlings pretreated with $200 \mu \mathrm{M}$ ABA and $200 \mu \mathrm{M}$ fluridone, respectively, for $24 \mathrm{~h}$ before the seedlings were treated with drought. GBSSI mRNA was determined by Northern blot hybridization. C - indicated the control sample that was kept in culture medium. Drought indicated that seedlings were air-dried for $12 \mathrm{~h}$ before the leaf samples were harvested.

\section{References}

Asaoka, M., Kazutoshi, O., Fuwa, H.: Effect of environmental temperature at the milky stage on amylose content and fine structure of amylopectin of waxy and nonwaxy endosperm starches of rice (Oryza sativa L.). - Agr. biol. Chem. 49: 373-379, 1985.

Ashraf, M., Hafeez, M.: Thermotolerance of pearl millet and maize at early growth stages: growth and nutrient relations. - Biol. Plant. 48: 81-86, 2004.

Cao, H., James, M.G., Myers, A.M.: Purification and characterization of soluble starch synthases from maize. Arch. Biochem. Biophys. 373: 135-146, 2000.

Chinnusamy, V., Khanna-Chopra, R.: Effect of heat stress on grain starch content in diploid, tetraploid and hexaploid wheat species. - J. Agron. Crop Sci. 189: 242-249, 2003.

Chu, C., Lee T.M.: The relationship between ethylene biosynthesis and chilling tolerance in seedlings of rice (Oryza sativa). - Bot. Bull. Acad. sin 30: 263-273, 1989.

Cohen, P.: The structure and regulation of protein phosphatase. - Annu. Rev. Biochem. 58: 453-508, 1989.

Dian, W., Jiang, H., Chen, Q., Liu, F., Wu, P.: Cloning and characterization of the granule-bound starch synthase II gene in rice: gene expression is regulated by the nitrogen level, sugar and circadian rhythm. - Planta 218: 261-268, 2003.

Dian, W., Jiang, H., Wu, P.: Evolution and expression analysis of starch synthase III and IV in rice. - J. exp. Bot. 56: 623632, 2005.

Dry, I., Smith, A.M., Edwards, A., Bhattacharyya, M., Dunn, P., Martin, C.: Characterization of cDNAs encoding two isoforms of granule-bound starch synthase which show showed that the accumulation of GBSSI transcript was reduced by ABA treatment (Fig. 4). In order to determine whether the signal transduction of drought-related GBSSI expression was ABA-dependent or independent, ABA and ABA biosynthesis inhibitor, fluridone, were applied to culture medium before seedlings were treated with drought stress. The result indicated that exogenous ABA slightly enhanced the drought effect on GBSSI expression (Fig. 5, lane 3); however, fluridone was inefficient to improve the effect of drought stress on GBSSI expression (Fig. 5, lane 4). Since fluridone $(200 \mu \mathrm{M})$ was shown to reduce the ABA synthesis in rice seedlings (Hsu and Kao 2003), the ineffectiveness of fluridone to affect the drought effect on GBSSI expression might not be the result of inability of fluridone to reduced the amount of endogenous ABA. Therefore, the result suggested that the signal transduction of drought stress to affect the GBSSI expression might be ABA-independent. However, we could not rule out the possibility that the effect of drought stress on GBSSI expression might be coordinated between both ABA-dependent and ABA-independent pathway; in this case, the drought effect could not be recovered when only the ABA-dependent pathway was blocked. In the future, studies on the interaction between rice GBSSI promoter and stress-responsive transcription factors should be helpful to furthermore elucidate the regulatory mechanism of GBSSI expression controlled by environmental and ABA stresses.

differential expression in developing storage organs of pea and potato. - Plant J. 2: 193-202, 1992.

Geigenberger, P., Muller-Rober, B., Stitt, M.: Contribution of adenosine 5'-diphosphoglucose pyrophosphorylase to the control of starch synthesis is decreased by water stress in growing potato tubers. - Planta 209: 338-345, 1999a.

Geigenberger, P., Reimholz, R., Deiting, U., Sonnewald, U., Stitt, M.: Decreased of expression sucrose phosphate synthase strongly inhibits the water stress-induced synthesis of sucrose in growing potato tubers. - Plant J. 19: 119-129, 1999b.

Hirano, H.Y., Sano, Y.: Enhancement of Wx gene expression and the accumulation of amylose in response to cool temperature during seed development in rice. - Plant Cell Physiol. 39: 807-812, 1998.

Hsu, Y.T., Kao, C.H.: Role of abscisic acid in cadmium tolerance of rice (Oryza sativa L.) seedlings. - Plant Cell Environ. 26: 867-874, 2003.

Jiang, H.W., Dian, W.M., Wu, P.: Effect of high temperature on fine structure of amylopectin in rice endosperm by reducing the activity of the starch branching enzyme. Phytochemistry 63: 53-59, 2003.

Keeling, P.L., Bacon, P.J., Holt, D.C.: Elevated temperature reduces starch deposition in wheat endosperm by reducing the activity of soluble starch synthase. - Planta 191: 342348, 1993.

Manners, D.J.: Starch. In Biochemistry of Storage Carbohydrates in Green Plants. - Academic Press, London 1985.

Marshall, J., Sidebottom, C., Debet, M., Martin, C., Smith, A.M., Edwards, A.: Identification of the major starch 
synthase in the soluble fraction of potato tubers. - Plant Cell 8: 1121-1135, 1996.

Mérida, A., Rodríguez-Galán, J.M., Vincent, C., Romero, J.M.: Expression of the granule-bound starch synthase I (Waxy) gene from snapdragon is developmentally and circadian clock regulated. - Plant Physiol. 120: 401-409, 1999.

Pathre, U.V., Sinha, A.K., Shirke, P.A., Ranade, S.A.: Diurnal and seasonal modulation of sucrose phosphate synthase activity in leaves of Prosopis juliflora. - Biol. Plant. 48: 227-235, 2004.

Seki, M., Narusaka, M., Ishida, J., Nanjo, T., Fujita, M., Oono, Y., Kamiya, A., Nakajima, M., Enju, A., Sakurai, T., Satou, M., Akiyama, K., Taji, T., Yamaguchi-Shinozaki, K., Carninci, P., Kawai, J., Hayashizaki, Y., Shinozaki, K.: Monitoring the expression profiles of 7000 Arabidopsis genes under drought, cold and high-salinity stresses using a full-length cDNA microarray. - Plant J. 31: 279-292, 2002.

Shinozaki, K., Yamaguchi-Shinozaki, K.: Molecular responses to dehydration and low temperature: differences and crosstalk between two stress signaling pathways. - Curr. Opinion Plant Biol. 3: 217-223, 2000.

Shinozaki, K., Yamaguchi-Shinozaki, K., Seki, M.: Regulatory network of gene expression in the drought and cold stress responses. - Curr. Opinion Plant Biol. 6: 410-417, 2003.

Sun, W., Van Montagu, M., Verbruggen, N.: Small heat shock proteins and stress tolerance in plants. - Biochim. biophys. Acta 1577: 1-9, 2002.

Suzuki, Y., Sano, Y., Hirano, H.Y.: Isolation and characterization of a rice mutant insensitive to cool temperatures on amylose synthesis. - Euphytica 123: 95100, 2002.

Tsai, C.Y.: The function of the Waxy locus in starch synthesis in maize endosperm. - Biochem. Genet. 11: 83-96, 1974.

Wang, S.J., Yeh, K.W., Tsai, C.Y.: Molecular characterization and expression of a starch granule-bound starch synthase gene in the sink and source tissues of sweet potato. Physiol. Plant. 106: 253-261, 1999.

Wang, S.J., Yeh, K.W., Tsai, C.Y.: Regulation of starch granule-bound starch synthase I gene expression by circadian clock and sucrose in the source tissue of sweet potato. - Plant Sci. 161: 635-644, 2001.

Wang, S.J., Yeh, K.W., Tsai, C.Y.: Circadian control of sweet potato granule-bound starch synthase I gene in Arabidopsis plants. - Plant Growth Regul. 42: 161-168, 2004.

Wilhelm, E.P., Mullen, R.E., Keeling, P.L., Singletary, G.W.: Heat stress during grain filling in maize: effects on kernel growth and metabolism. - Crop Sci. 39: 1733-1741, 1999.

Xiong, L., Schumaker, K.S., Zhu, J.K.: Cell signaling during cold, drought, and salt stress. - Plant Cell 14 (Suppl): S165S183, 2002. 